\title{
SUPPLY CHAIN INTELLIGENCE AND VALUE CREATION: A FRAMEWORK
}

Ganesh Vaidyanathan, Indiana University South Bend, gvaidyan@iusb.edu

Asghar Sabbaghi, Indiana University South Bend, Sabbaghi@iusb.edu

\begin{abstract}
Supply chain management has enabled organizations to accelerate many of the manual processes and information flows. In recent years, more emphasis has been placed on supply chain intelligence to identify new opportunities, win new businesses, and support optimal decisions to achieve competitive advantage. In this study, we have formulated a framework of value creation in supply chain management and supply chain intelligence using factors of Kaplan-Norton balance scorecard framework. This study will be used to further understand and analyze supply chain intelligence in future empirical research.
\end{abstract}

Keywords: Decision Support Systems, Supply Chain Intelligence, Value creation, Framework, Scorecard, Metrics

\section{INTRODUCTION}

Supply chain intelligence (SCI) is based on extracting and generating intelligent and meaningful information for decision makers from the enormous amounts of data generated and captured by supply chain management (SCM) systems. Data collected across the supply chain is analyzed and the result from the analysis can be turned into strategic information for the organization. Strategic information on supply chain networks can be provided to decision makers in order to strategize and reconfigure supply chain networks. SCI solutions turn data into information and knowledge, enabling companies to develop unique demand, supply, operational and customer insights. This results in improved efficiency and effectiveness in firms. SCI enables companies to anticipate customer demand, gain financial insights across the extended supply chain network, improve product quality, optimize supply chain strategies, leverage existing information systems, and above all, create value for all who participate in supply chain.

Value creation in supply chain has attracted considerable attention in the literature and particularly has been viewed as one of the key elements for enhancing organizational effectiveness and competitive advantage. However, the fundamental question is how firms define and measure value creation, and how supply chain intelligence contributes to value proposition. In this study, we propose a SCI and value creation framework. By proposing a framework of SCI, this study focuses on value creation of supply chain networks. The paper is organized as follows: the definition of value creation is discussed in the next section. The following section discusses a newly proposed framework on SCI. The study concludes with research implications and future research.

\section{VALUE CREATION IN SUPPLY CHAIN MANAGEMENT}

Porter's well-known value chain model [1] and the corresponding notion of value systems have profoundly influenced the perception of how supply relationships work. The original focus of Porter's value chain was an organization that converts raw materials into products where the value of products in marketplaces is the vehicle that creates differentiation from competitors' products. Martinez [2] presents two perspectives of value that includes shareholder perspective or internal value where value equals to wealth, and customer perspective or external value where value equals to satisfaction. An organization should be creating wealth for its shareholders while satisfying its customers' expectations, hence creating value for both parties.

Building on Thompson's [3] typology of long-linked, intensive, and mediating technologies, Stabell and Fjeldstad [4] explained that value shop, value chain, and value network are three distinct generic value configuration models required to understand and analyze firm-level value creation logic across a broad range of industries and firms. They explain that the value shop configuration is firm's reliance on intensive technology to solve a customer or client problem similar to automobile mechanic shops. According to the study, value shops are characterized by selection, combination, and order of application of resources and activities so as to be dimensional and appropriate to customer solutions. Dell, the computer company, may be represented by value shop configuration as their value creation logic is clearly re-solving of customer problems as they focus on customer needs, desire, and interests accounts for the distinctive nature of its approach compared to its competitors in the industry. Stabell and Fjeldstad [4] have also proposed value network configuration as 
another alternative to value chain, particularly in response to concerns about the applicability of the value chain to transaction-based service structures. Telecommunications, insurance, and retail banking industries configure themselves to mediate interactions and exchanges across a network of their customers by admitting members and by establishing, monitoring, and terminating direct or indirect relationships among members. In this model, alignment of the size of network infrastructure with the size of the customer pool and customers use of service is the key to network value. The value network model captures value created in transaction services when firms provide networking services to customers. Value chain is embedded in a system of interlinked value chains [1]. This value system includes the value chain of suppliers and the value chain of distinct distribution channels.

Value creation in supply chain is accomplished by a value system that encompasses value chain, value shop, and value network. According to Brititci et al [5], if one considers supply chain management as simply the management of the logistics operations of a company both upstream and downstream, the value propositions of supply chain members become disjoined as they focus on value deliverance to the next members in the chain instead of overall value proposition important to the end customer. Each participating company operating as an individual enterprise tries to maximize its own corporate goals, and therefore sub-optimizing the overall performance. They define an extended enterprise (a knowledge-based organization) and a virtual enterprise (temporal knowledge-based organization) that use the distributed capabilities, competencies and intellectual strengths of its members to gain competitive advantage in order to maximize the performance of the overall extended or virtual enterprise. Craighead and Shaw [6] have proposed a business model of electronic commerce in a supply chain based upon a resource-based view of a firm. The model demonstrates that information technology can be used to add value to the final consumer by adding both direct and indirect value at multiple points in the supply chain. Allee [7] expands the concept of a value network that generates economic value through complex dynamics exchanges between one or more enterprises, customers, suppliers, strategic partners and the community. These networks include not only the value of transactions around goods, services, and revenue, but also the knowledge and intangible value exchanges. We will use value creation as defined by these scholars in our framework.

\section{SUPPLY CHAIN INTELLIGENCE}

Decision support systems (DSS) constitute a class of computer-based information systems that support decision-making activities in organizations. According to Power [8] data-driven DSS or dataoriented DSS manipulates internal company data and, sometimes, external data. Business Intelligence (BI) is used in analyzing business data to support better business decisions and therefore a form of DSS. Golfarelli et al. [9] define BI as the result of in-depth analysis of detailed business data using knowledge management, ERP, decision support systems and data mining tools and techniques. SCI refers to the use of information technology to collect and effectively use information to improve business potency. SCI results from BI that provides capability to access, analyze, and share information across the supply chain network. Using analytics and standardized metrics in supply chain processes such as procurement, manufacturing, and distribution, firms can gain critical insight into their supply chains, reducing costs, increasing revenues, and satisfying customers and partners. For example, procurement managers cannot rely only on least-cost suppliers to be competitive. Instead, they must develop comprehensive sourcing strategies, optimize supplier relationships, and proactively plan risk mitigation to gain greater visibility of their supply chain. Maytag utilizes consumer feedback from warranty forms to capture the essence of consumer experience. Information derived from warranty analysis is used to support ongoing quality initiatives. Organization's employees, partners, and suppliers need easy access to information to analyze and share information with others [10]. Procurement specialists can analyze trends over time such as corporate spending history, budget performance, usage patterns, and changes in supplier dependencies to rank suppliers. Supplier ranking provides organizations an objective and flexible measuring system that reliably identifies the best supplier and effective responds to changing business conditions. SCI can also provide an organization a concise "dashboard" to visually present time-based key performance indicators (KPIs). This enables managers to view external performance as well as internal performance at all levels of supply chain process. Further, optimization that results from SCI can be used to examine suppliers in aggregate to reduce risk exposure, minimize purchasing costs and increase negotiating leverage. Scenario planning from SCI can be used to evaluate all options and help an organization to find opportunities and identify new and more efficient processes. Alcon's surgical procedure trays are manufactured to customer's unique specifications and 
contain virtually every item a surgeon will need for a single surgery. Alcon's forecasting system, powered by SAS, Inc., tracks customer usage and demand patterns to establish a unique forecast for each surgical procedure tray. The company attributes a major portion of their market share growth to their SCI forecasting solution [11]. SCI is extracted from internal data of organizations that create value for organizations. We plan to group such value creating knowledge from various forms of data that are available in organizations to form our framework explained in the next section.

\section{FRAMEWORK OF VALUE CREATION AND SUPPLY CHAIN INTELLIGENCE}

Kaplan and Norton [12] have articulated a framework that helps any participant in supply chain to translate its vision and strategies into value creation proposition and processes from four different perspectives that includes financial, customer, internal process, and learning and growth for targeted customers such as customer satisfaction, customer retention, customer acquisition, and customer profitability. The internal process perspective identifies the critical processes that are expected to have the greatest impact on the strategy. And finally, the learning and growth perspective identifies the intangible assets such as human capital (employee skills, talent, and knowledge), information capital (information system, databases, networks, and technology infrastructures), and organization capital (culture, leadership, employee alignment, teamwork, and knowledge management) that are required to support value creating internal processes. By considering Kaplan and Norton framework [12], one can describe the contribution of SCI to value creation in a supply chains with respect to financial, customer, internal process, and learning and growth perspectives. SCI seeks to enable any supply chain participant to have relevant information or knowledge and intelligence about the market and customer for specific product or service, supply sourcing, internal processes, and the capabilities of

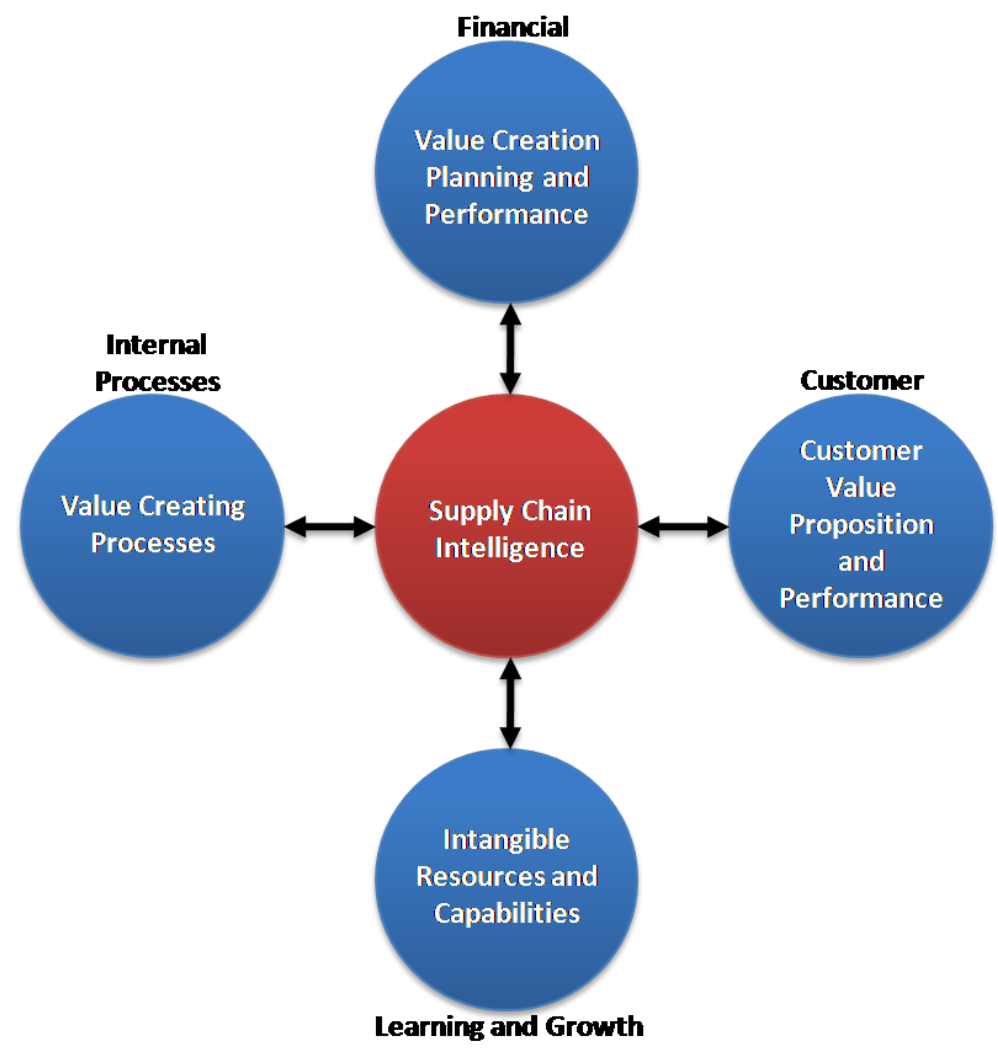

Figure 1 Value Creation and Supply Chain Intelligence Framework

perspective. The financial perspective describes the tangible outcomes of the strategy in traditional financial measures such as ROI, shareholder value, profitability, revenue growth, and cost per unit. The customer perspective defines the value proposition intangible resources such as human, informational, and organizational capital. In particular, SCI technologies provide strategic information and intelligence to answer "what-if" scenarios for reconfiguration of key functions and processes in 
sourcing, operations, and distribution. This demands data integration infrastructures that provide capability to extract, transform, and mine data from multiple enterprise sources like enterprise resource planning (ERP), customer relationship management (CRM), SCM, and other data sources and business intelligence applications. As seen in Figure 1, SCI seeks to enable supply chain participants to have relevant information, knowledge, and intelligence about the market, customer value proposition and performance, supply sourcing, internal processes, and other value creating processes, and intangible capabilities and resources such as human, informational, and organizational capital.

From a financial perspective, firms can generate value through revenue growth and productivity. Revenue growth can be generated by deepening relationships with existing customers for better sales of existing products or services, new products or services, or by productivity improvement that can occur by lowering direct and indirect expenses. Productivity can also be improved through reducing costs by utilizing financial and physical assets more efficiently. SCI seeks to provide timely and relevant knowledge and intelligence to reduce risk and to optimize financial decisions that contribute to value creation through revenue growth and productivity.

From a customer perspective, supply chain participants should create differentiated, sustainable value to targeted customer segments through a set of common customer outcome measures. The value proposition from customer perspective defines the company's strategy for the customer by describing the unique mix of product, price, service, relationship, and image that a company offers its targeted group of customers. Kaplan and Nolan [12], for example, argue that Southwest Airline, Dell, WalMart, McDonalds, and Toyota have been extremely successful by offering customers the best buy or lowest cost in their categories. On the other hand, they note that companies such as Sony, Mercedes, and Intel follow a value proposition emphasizing on product innovation and leadership and therefore command high prices, above average in their categories since they offer products with superior functionality. SCI, through CRM, contributes value by improving customer responsiveness, increasing flexibility for changing market conditions, identifying targeted market or customer, improving customer services and satisfaction, increasing customer retention, and marketing effectively and efficiently. In particular, intelligence embedded through the collaborative processes would enable business to reduce costs, create more value for customers, and detect critical demand changes quickly enough to design and execute optimal responses.

From internal process perspective, companies participating in the supply chain can deliver the differentiated value proposition through managing their internal processes and their development of human resources, information resources, and organizational capabilities. These internal processes may be classified into operational management, customer management, innovation, and regulatory and social processes. In this perspective, a company, in order to create value, should identify the processes that are most appropriate for their specific strategies. For example, companies following a product leadership strategy would stress excellence in their innovation processes; companies following a low total cost strategy must excel at operating processes; and companies following customer solutions strategies will emphasize their customer management processes [12]. SCI enables the supply chain participants to evaluate internal processes and identify area for improvement in these processes through redesign and reengineering projects, allows members to collaborate in design and development of processes in operations and logistics, distribution strategies, and all related forms of supply chain planning. Participating firms would experience sustainable cost savings through increased productivity and streamlined business processes in procurement and purchasing, order fulfillment, account receivable and payable and exception management. These functions would contribute many value-added capabilities to their communities including commerce, business, and enablement.

From the learning and growth perspective, SCI can create value by enabling supply chain participants' human, informational, and organizational capital to adopt effective strategies and decisions. As part of information capital portfolio, SCI would contribute to value creation through technology infrastructure and various applications such as transaction processing, analytic knowledge, and transformational applications. For example, SCI would empower employees using techniques such as data mining, text mining, and machine learning to extract timely and relevant knowledge or intelligence about each customer's total relationship with the company, or about a segment or individual important customer so that they can judge how much to be expended not only to satisfy the customers on existing relationship, but also on learning about how to satisfy emerging needs from those customers. Employees in operations side of business would have timely and accurate 
intelligence about the customers purchasing new products or services, and their feedback so that they would be able to sustain improvement programs where they can systematically report defects and accurate cost, time and waste out of production systems. SCI would empower human resources in supply chain participants to evaluate various business processes and partnership in the chain along with organizational alignment, and to adopt an optimum supply chain strategy in the context of business vision. This would result in value creation through four key areas: (1) innovation and growth to meet customer demand for constant stream of new products and to stay ahead of competitors, (2) value chain optimization by focusing on core competencies to find external partners with other best-in-class capabilities, (3) risk management to protect themselves from supply disruptions, and (4) advanced-cost management techniques to evaluate best prices and quality of products or services that match purchases to needs and reduce total cost of ownership. For example, in 2002, Dell anticipated the west Coast Dock strike six month before the ports closed and chartered a fleet of 747 locking-in freight rates at half of spot-market peaks. It also worked with suppliers to ensure that parts were delivered on time to Shanghai and Taipei airports to minimize costs [13].

Holcim, one of the largest manufacturers and suppliers of cement and mineral components in the United States, initially conducted an analysis of how to deliver e-commerce solutions to their customers. However, its aspiration was to create a knowledge sharing platform where any member of the community of cement and its consumers (concrete producers, distributers, engineers, architectures) would be able to not only transact business (place orders, pay online) but also be able to, among others, share and exchange knowledge about cement order forecasts and their experiences with specific applications. The company's customer knowledge managers conducted meetings with various selected customers to discuss current and emerging trends in the cement industry and the potential impact of these developments on Holcim's customers so that jointly they ascertain how the company could create value for their customers. The Customer were impressed with company's approach in talking to them as this made them to feel ownership in their project and no other supplier had done so [14].

Strategic supply chain management demands collaboration among all participants in value creation processes and functions that focus on global optimization. Any participant in a supply chain cannot optimize their own operations without understanding the real-time demands of all subsequent customers in the chain as well as the current constraints on its all suppliers downstream in the chain.

\section{IMPLICATIONS AND FUTURE RESEARCH}

While supply chain management has enabled organizations to accelerate many of the manual processes and information flows such as purchase order, invoices, inventory counts among others, more emphasis should be placed on SCI to identify new opportunities, to win new businesses, to support optimal decisions predicting value creation of opportunities and resources, and to achieve competitive advantage. In other words, SCI should leverage both internal and external ERP and SCM data to uncover unique demand, supply, operational and customer-related insights. SCI can be used to predict better manufacturing performance, warranty failures, procurement spend, and customer patterns especially under uncertain conditions. The process of competitive intelligence according to Kahaner [15] is the action of gathering, analyzing, and applying information about products, competitors, suppliers, regulators, partners, and customers for the short-andlong-term planning needs of an organization. How SCI when used for CI process results in better profit margins can be studied using a longitudinal data analysis.

To meet expected SCI requirements of a decision maker in various areas of supply chain process and to evaluate value creation using SCI, further research needs to be undertaken to collect data and understand relationships framework factors. SCI requirements would also differ based on the type of industry and its supply chain characteristics, and may require specific tools and techniques. Value creation of SCI tools and techniques can be studied from financial, customer, internal processes, and from learning and growth perspectives as directed by our framework.

\section{CONCLUSION}

In this study, we have formulated a framework of SCI and value creation in supply chain management using Kaplan-Norton balance scorecard framework. This framework can be used by practitioners to understand how SCI creates value in their organizations. Value created in the lens of financial, customer, internal processes, and from learning and growth perspectives has been practiced by firms all over the world using the Kaplan-Norton balance scorecard framework. The criticism on Balance 
Scorecard is that the balanced scorecard provides just the metrics and does not provide a bottom line score to distinguish winners from losers and is just a dashboard [16]. Our framework described in this study is indeed a dashboard to tell managers many interesting facts about their supply chain and does not give a score for the organization's supply chain performance. SCI through the lens of this framework has the capability of providing critical advantages to organizations by enabling them to develop unique insights about their demand patterns, supply networks, operations and customer service requirements. SCI has the capability of combining data from various sources, such as transactional and operational systems, to provide more comprehensive analysis and reporting to better meet corporate business requirements. This would contribute to the efficiency and effectiveness of the overall supply chain, by increasing profits and higher customer satisfaction.

\section{REFERENCES}

1. Porter, M. E. 1985. Competitive Advantage. New York, NY: The Free Press.

2. Martinez, V. (2003). Understanding value creation: the value matrix and the value cube. $\mathrm{PhD}$. Thesis, Strathclyde University. Glasgow.

3. Thompson, J. D. 1967. Organizations in Action. New York, NY: McGraw Hill.

4. Stabell, C. B., \& Fjeldstad, O. D. (1998). Configuring value for competitive advantage: on chains, shops, and networks. Strategic Management Journal, 19, 413-43.

5. Brititci, S. U., Martinez, V., Albores, P., \& Parung, J. (2004). Creating and managing value in collaborative networks. International Journal of Physical Distribution \& Logistics Management, 34 (3/4), 251-268.

6. Craighead, C. W., \& Shaw, N. G. (2003). ECommerce value creation and destruction: a resource-based, supply chain perspective. The Database for Advances in Information Systems, 34 (2), 39-49.

7. Allee, V. (2000). Reconfiguring the value network. Journal of Business Strategy, 21 (4), 36-39.

8. Power, D. J. (2002). Decision Support Systems: Concepts and Resources for Managers. Westport, Conn.: Quorum Books.

9. Golfarelli, M., Rizzi, S., \& Cella, I. (2004). Beyond data warehousing: what's next in business intelligence? Proceedings of the 7th ACM international workshop on Data warehousing and OLAP, Washington, DC, November 12 - 13, 2004.

10. Sahay, B.S., \& Ranjan, J. (2008). Real time business intelligence in supply chain analytics. Information Management \& Computer Security, 16 (1), 28-48.

11. SAS. (2010). Alcon Sees High Customer Service, Optimized Inventory Levels. Accessed at http://www.sas.com/success/alcon.html on April 25, 2010.

12. Kaplan, R. S., \& Norton, D. P. (2004). Strategy Maps: Converting Intangible Assets into Tangible Outcome. Boston, MA: Harvard Business School Publishing Corporation.

13. Blascovich, J. D., \& Markham, W.J. (2005). How procurement excellence. Supply Chain Management Review, 44-52.

14. Gibbert, M., Feibold, M., \& Probst, G. (2002). Five styles of customer knowledge management, and how smart companies use them to create value. European Management Journal, 20 (5), 459-469.

15. Kahaner, L. (1998). Competitive Intelligence: How to Gather, Analyze and Use Information to Move Your Business to the Top. New York, NY: Touchstone.

16. Jenson, M.C. (2001). Value maximization, stakeholder theory, and the corporate objective function. Journal of Applied Corporate Finance, $14(3), 8-21$. 